\title{
MUSEUS E DIVERSIDADE SEXUAL REFLEXÕES SOBRE MOSTRAS LGBT E QUEER
}

Renato Pinto

renatolarp@gmail.com
Doutor em História Cultural. Pesquisador associado do Laboratório de Arqueologia Romana Provincial - LARP. Pós-doutorando do Museu de Arqueologia e Etnologia da Universidade de São Paulo - MAE-USP. Bolsista FAPESP.

\section{R E S U M O}

Esta breve reflexão está focada no tema das exibições em museus que buscam mostrar artefatos, a história e a memória de grupos LGBT-Q (lésbicas, gays, bissexuais, transgêneros e queer). Interessa-me relatar - sem a pretensão de acentuado aprofundamento nas discussões teóricas ou de exaustiva apresentação de exemplos - algumas das inquietudes e soluções criativas que se apresentam aos curadores e organizadores de mostras que contenham acervo erótico ou de cunho sexual que possam ser associados aos grupos LGBT-Q inclusive mostras sobre a Antiguidade. Parte desta reflexão é resultado de um trabalho que desenvolvo desde o inicio de meu doutoramento no campo da História Cultural.

Palavras-chave: Teoria Queer, LGBT, museus.

De uma forma geral, há poucas mostras em museus que tratam especificamente de sexualidade humana, e que deem muita atenção aos temas ligados aos indivíduos ou grupos LGBT (lésbicas, gays, bissexuais, transgêneros). Os membros de comunidades marginalizadas muitas vezes por suas práticas sexuais dissonantes das normas sociais, progressivamente identificados como queer a partir da década de 1980, não logram encontrar nas exibições dos museus muitas referências aos seus estilos de vida e às suas experiências e conquistas. Sua história é silenciada ou simplesmente ignorada. Nos museus britânicos, embora tenha surgido um interesse maior pelo tema, é um fenômeno dos últimos dez anos, apenas (FROST, 2010: 138).

Para os estudos da diversidade sexual humana, e a fim de promover a inclusão e integração das populações LGBT (e devemos incluir aqui o ' $Q$ ' de queer à sigla), a cultura material presente nas mostras temporárias ou permanentes possuem um enorme potencial transformador social. Uma vez que a cultura material é parte ativa e inseparável do ser humano, ela oferece um campo rico para os estudos das diversidades e das construções e desconstruções dos discursos histórico-arqueológicos (JENKINS, 1991: 256; HODDER, 2005: 255). Enquanto criação humana que resulta de contextos culturais, a cultura material é afetada por muitas negociações de interesses e significados fluidos, como identidade, gênero, sexualidade, entre outros fatores. Contudo, ela não é passiva (FUNARI, 2005: 1). Antes, a cultura material tem força própria para mudar o comportamento do ser humano, criando novos contextos sociais e novos cenários culturais (TILLEY, 1998: 325-6). Assim, o papel exercido pelo museu e seus acervos materiais na 
preservação do patrimônio cultural também implica sua atuação no campo da transformação das sociedades.

\section{MUSEUS NO PÓS-MODERNISMO}

O museu pode afetar de maneira direta ou indireta a interpretação do passado, produzindo distorções advindas da seleção e classificação dos artefatos, em um movimento de criação de narrativa histórica. Os museus produzem discursos sobre a relação entre os visitantes e os objetos exibidos e reside na disposição e na seleção de tais artefatos o interesse para que façam sentido ao visitante. Para a cognição, há um consciente sistema de apresentação e de visualização em prática (SHANKS \& TILLEY, 1992: 68). O museu, desta forma, é o resultado de um complexo processo que é conduzido antes que o acervo seja exposto. Em uma abordagem pos-modernista/ pós-processualista, não se espera que haja a concepção de um passado objetivo, livre de preconceitos, por parte de arqueólogos e curadores. Toda apresentação de artefatos é retórica de persuasão, uma mobilização ativa de modos particulares de apresentação que encobre as distâncias entre o passado e o presente. Os artefatos são comumente organizados cronologicamente, mas podem surgir unidos por sua taxonomia. De qualquer forma, a cultura material parece refletir sobremaneira o sistema arqueológico, não seu uso pelas pessoas em algum momento de sua trajetória histórica fora dos museus. Não raramente, a subjetividade do artefato lhe é negada pela catalogação (SHANKS \& TILLEY, 1992: 69, 70), que pressupõe um controle científico refratário a qualquer questionamento sobre sua natureza empírica. Todavia, a subjetividade é um elemento inerente às escolhas feitas por arqueólogos e curadores. Como apontava Roland Barthes, um inventário nunca é algo neutro: inventariar é se apropriar (BARTHES, 1986: 222).

O museu, de forma paradoxal, preserva o presente, pois o passado está ausente e o artefato significa tal ausência: é somente representação (SHANKS \& TILLEY, 1992: 76. Muitas vezes o passado torna-se não uma réplica, mas um simulacro, uma cópia de algo que nunca existiu, e, desta feita, o passado se transforma em sua própria imagem (SHANKS \& TILLEY, 1992: 79. Não se pode dizer, contudo, que o museu consegue (ou que deseje) condicionar todas as visões (SHANKS \& TILLEY, 1992: 85., mas muitos museus dão ênfase na cientificidade dos métodos de descoberta e de classificação (SHANKS \& TILLEY, 1992: 88. e o passado, muitas vezes, é apresentado como fixo, imutável, ainda que se possa admitir que sua interpretação seja variável por causa da "falha" da subjetividade do arqueólogo, afetado por seu presente. (SHANKS \& TILLEY, 1992: 90. Mas essa visão que propugna a existência de um passado objetivo e homogêneo, empírico, não se sustenta.

$\mathrm{Na}$ medida em que não parece haver um presente homogêneo reconstruindo o passado, pode-se argumentar que também não haja um passado genuíno para ser retratado. Assim, o museu é figurativo e retórico, é seu ato de interpretação e de persuasão que dá sentido às exibições. (SHANKS \& TILLEY, 1992: 95. O artefato é também transitório, precário, e não se pode afirmar que exista um método universal ou que haja princípios formais de interpretação e de exibição de artefatos. O museu costuma suprimir as contradições (SHANKS \& TILLEY, 1992: 96 e 97), mas poderia servir de fonte para o estudo das construções ideológicas. Enquanto as mostras 
estão intimamente ligadas ao presente, o processo ideológico não deve ser apagado, e a maneira como as sociedades construíram suas identidades ao longo da história deveria estar aparente. Não se espera que o museu apague suas ideologias passadas, como sugeriu Ruy Barbosa (MENESES, 1995: 108). O processo de construção tem de estar presente e o visitante deveria participar desta incessante construção, em conjunto com o curador e o arqueólogo. Da mesma forma, o contexto político da trajetória do objeto deve constar em conjunto com o contexto político do museu e da mostra no presente (SHANKS \& TILLEY, 1992: 98).

Opós-modernismo/pós-processualismoabriucaminhoparaabordagens interpretativas múltiplas do passado, que mostram a mulher e outras formas de gênero ativamente envolvidas na criação da tessitura social, e na criação da cultura material de sociedades desaparecidas (WHITLEY, 1998: 219). Podese observar, entretanto, que ainda há certa relutância em abraçar os temas dos gêneros e da diversidade sexual nos estudos de cultura material, e que a prática arqueológica ainda retém muito de seu discurso hetero-androcêntrico (KNAPP, 1998: 241; NELSON, 2005: 131). Esta é uma constatação perturbadora e contundente, em especial quando se fala de estudos de grupos LGBT-Q.

\section{ARQUEOLOGIA QUEER}

As preocupações da Arqueologia com grupos LGBT e queer estão associadas ao movimento feminista e aos estudos de gênero, ainda que as lutas sociais dos seus participantes possam ter tido origens distintas. A publicação de Conkey \& Spector (1984) "Archaeology and the Study of gender", é tida como o gênesis da Arqueologia Feminista, seguida, mais tarde por outros influentes trabalhos relacionados aos estudos de gênero, como o de Gero \& Conkey (1991), Engendering Archaeology. Tais estudos tiveram inspiração feminista e denunciaram a ausência das experiências e conquistas das mulheres nos discursos populares e acadêmicos como um mecanismo por meio do qual uma ideologia patriarcal se replicava, privilegiando a experiência masculina (VOSS, 2000: 181).

Outro fenômeno acontecia paralelo ao surgimento da Arqueologia feminista e de gênero: a AIDS. Paralelo num primeiro momento, diga-se, mas que logo se ligaria a muitos estudiosos do tema do feminismo e das relações de gênero. A AIDS jogou de supetão nas manchetes dos meios de comunicação termos que circulavam com mais frequência apenas nos guetos das subculturas das minorias ou nos trabalhos voltados a elas: homossexualidade, sadomasoquismo, lesbianismo, prostituição, transgêneros e transexuais. Nos meios acadêmicos dos estudos sobre a sexualidade humana, o resultado dessa exposição foi a percepção de que as teorias de gênero não davam conta da pluralidade e da diversidade das identidades sexuais. A sexualidade passou a ser estudada como um aspecto social distinto, não uma mera extensão do gênero.

Nesta nova constelação, as minorias passaram a ser associadas ao conceito de queer, ou seja, aquilo que estava em confronto com as normas estabelecidas pela maioria. Nas décadas de 1940 e até os anos 1970, o termo queer era uma invectiva comum àqueles tidos pela sociedade americana como pecadores, pervertidos, desviantes das normas da respeitabilidade: os homossexuais e efeminados, em geral. Na língua inglesa atual, em especial na América do Norte, os termos faggot (para homens homossexuais) e 
dyke (para lésbicas) algo como que tomaram esse papel classificador. Por outro lado, o termo gay foi transformado para se adequar a identidades reconhecidas pelos próprios homossexuais, a fim de representar sua própria condição de grupo minoritário. Mas, à medida que a universalidade da palavra gay não parecia, outrossim, dar conta das variantes identitárias da sexualidade não heteronormativa, certos grupos não mais se sentiram identificados com ela: caso das lésbicas, dos transexuais e daqueles que não se encaixavam no termo, como os grupos dos ursos (bears), por exemplo. Além disso, o termo gay parecia cada vez mais se referir aos homossexuais masculinos, apenas.

O advento da AIDS escancarou também as diferenças entre as minorias e o termo queer resurge como uma tentativa de evitar as taxonomias engessadas, plasmadas. Movimentos norte americanos que repudiavam a ideia de imposição de normalidade como ACT UP, Queer Nation, The Pink Triangle respondiam a uma sociedade americana atravessada (GABRIEL, Peter, 2010: 71) pelo conservadorismo da era Reagan.

Os trabalhos de Sedgwick (1990), Epistemology of the Closet e de Judith Butler (1990), Gender Trouble, levaram a sexualidade para além dos limites dos gêneros, e são tidos como fundamentais para o surgimento e fortalecimento da teoria queer. A teoria queer, ou talvez devêssemos dizer teorias queer, não tratam apenas de gays e lésbicas, mas sim de indivíduos e grupos que não se enquadram nas conformações heteronormativas, tampouco se restringem a estudar tão somente fenômenos urbanos modernos. Podem mesmo ser alçadas para estudos sobre a Antiguidade, por exemplo (LEVIN, 2010: 51).

Os estudos feministas, de gênero e queer desestabilizam o preceito de que o mundo sempre foi e tem de ser dominado por um estrutura familiar heteronormativa, um cenário construído pelo capitalismo ocidental. Ao mesmo tempo, a diversidade humana não precisa apenas ser apresentada como negação. Seguindo um modelo foucaultiano de pensar, pode-se enfatizar as negociações e adaptações, mostrando que o poder não emana apenas do topo da pirâmide social, antes, mostra-se muito mais nuançado, e as dissidências e convoluções existem mesmo no interior de grupos tidos erroneamente como homogêneos no afã de tudo classificar (DOWSON, 2000: 163; CROUCHER, 2005: 611; COBB, 2005: 633-4). A adaptação, nem sempre fácil e livre de controvérsias, das teorias queer para aplicação aos estudos da cultura material fundou a Arqueologia queer (VOSS, 2000: 187).

A Arqueologia feminista e a de gênero compartilham de semelhanças com a Arqueologia queer. todas, ainda que surgidas em contextos políticos específicos, procuram, em alguma medida, rejeitar as taxonomias androcêntricas e as políticas de intolerância contra minorias sociais (VOSS, 2000: 182-5).

Mais especificamente, a Arqueologia queer foca seus esforços no intento de mostrar como a diversidade sexual humana deixou marcas no vestígio material (VOSS, 2000: 186). Da mesma forma, denuncia as ausências capciosas ou como os discursos arqueológicos da supremacia do homem branco heterossexual afetaram nossa forma de ver os vestígios do passado, assim como as práticas acadêmicas modernas (DOWSON, 2000: 162). 
Há séculos que as grandes coleções dos museus mais tradicionais da Europa e dos Estados Unidos vêm representando as vontades e as viagens de gentlemen abastados das nações colonizadoras. Também ali se mostram os espólios das conquistas e as narrativas de nacionalismo. Os grandes museus do Ocidente tiveram papel fundamental na construção da tríade "nacionalidade", "masculinidade' e "colonialismo". (LEVIN, 2010: 1,2. Mas as mulheres dos grandes homens capitalistas também visitavam museus. De fato, ao fim do sec. XIX, ir ao museu esteve associado a um lazer feminino, ressalvas àqueles pais e seus filhos que procuravam os museus "masculinos": exposições de armas, de dinossauros, museus de ciência, etc. (LEVIN, 2010: 2. Não deve passar despercebido o incremento no número de mulheres nos museus a partir do final do séc. XIX, e as próprias representações femininas nos acervos dos museus serviram de veículos para manifestações políticas com aspirações feministas, como o movimento das sufragistas na Inglaterra, que atacavam certas coleções que retratavam a mulher como um objeto social passivo e inferior ao homem. As sufragistas haviam compreendido que os acervos eram um receptáculo da propaganda do controle masculino que o governo, exercido por homens, aplicava aos museus (LEVIN, 2010: 2.

Mas com a Segunda Guerra, e a escassez de mão de obra masculina, o próprio trabalho nos museus se tornou mais feminino e criou-se mesmo a percepção de que homens afeminados também controlavam os museus, em especial aqueles de acervo de cunho artístico. Isso se dá a partir de estereótipos, de que locais tidos como femininos servem de abrigo para os profissionais homossexuais. O fato é que há pouquíssimas documentações da participação de funcionários LGBT nos museus. São silêncios que espelham distorções e extirpações que rodeiam a história das populações LGBT no Ocidente. E se há alguns exemplos de homossexuais masculinos enquanto colecionadores de renome, exceções que comprovam a regra, muito mais obscura é a participação de lésbicas e de transexuais em trabalhos que envolvem os museus (LEVIN, 2010: 3. Esse descompasso pode encontrar explicação no enorme preconceito que ainda cerca essas minorias e na permanência do sexismo machista, também. Embora o museu possa ser percebido por muitos como um local de mulheres, os homens ainda dominam as posições de poder e de doações, e há indícios de que os salários de funcionários é um pouco mais alto do que o de funcionárias nos Estados Unidos (SCHWARZER, 2010: 17).

Em algumas culturas mais hostis aos homossexuais, qualquer referência às sexualidades que não a heterossexual são obliteradas, como no Iraque e no Afeganistão, mas não somente. Em 2006, um diretor de um museu norte-americano foi mandado embora porque havia sido visto em um bar gay (SCHWARZER, 2010: 26) Apesar deste quadro desalentador, há alguns resultados positivos na maneira como os profissionais dos museus vêm sendo treinados. Hoje é possível debater em que medida os funcionários dos museus devem se instruir das técnicas de exibição de peças e o quanto devem estar inteirados das discussões teóricas sobre o patrimônio das populações comumente marginalizadas.

Estudar os debates teóricos sobre os museus e sua relação com a diversidade humana representa compreender como se dão as escolhas de temas, a forma de apresentar o acervo e a dinâmica da interpretação da cultura 
material exposta. As teorias feministas e os estudos queer apresentam um arcabouço para a autorreflexão e hoje se mostram ricas em suas abordagens que visam retratar a diversidade de forma diversa, justamente (LEVIN, 2010: 50. Como aponta Funari $(2007,104)$ :

A formação do profissional de museu [...] não se restringe ao saber
técnico, nem, menos ainda, ao domínio das artimanhas do micro-poder.
O desafio que se impõe é formar profissionais que sejam autônomos,
críticos, infensos à inércia, propensos à luta pela transformação. Aparente
paradoxo, que se busque a transformação, em uma profissão voltada
para a preservação.

Que artefatos melhor representariam a comunidade LGBT-Q? Com a AIDS, temia-se que a cultura material da população LGBT estaria muito mais presente nos memoriais do que em exibições mais autoafirmativas de acervos nos museus. Os traços de derrotas e de obliterações com precessão sobre os acervos que pudessem mostrar as conquistas sociais e políticas, as histórias e personalidades ligadas ao mundo LGBT-Q. Mas há hoje novas exibições que se concentram em mostrar tais coleções, embora um fato que logo se mostrou consternador e ao mesmo tempo revelador para alguns é o de que pode haver pouca ou nenhuma diferença entre a cultura material de heterossexuais e homossexuais (LEVIN, 2010: 4).

Então, o que se colocaria numa exibição queer, por exemplo? Cartas? Diários? Desenhos? Esculturas? Vestimentas? Em larga medida, são itens já encontrados em muitos museus que não se dedicam às minorias sexuais. Contudo, nos últimos anos, em especial nos museus britânicos, há um claro movimento para realçar e fomentar as coleções sobre a história e estilos de vida queer. Um exemplo é o da mostra de 2006, Queer Is Here, do Museu de Londres, que procurou retratar como as comunidades LGBT-Q se dedicam e reagem ao ativismo político, às questões de saúde, de aceitação própria (o outing), e ao bullying nas escolas, entre outros temas. Um dos motivos para esse renascer é a revogação em 2003 do Ato Governamental da cláusula 28, emitido em 1988, que proibia a "promoção" de homossexualidade em qualquer manifestação artística ou educativa que contasse com subsídios governamentais. Embora ainda hoje parte da mídia britânica ainda resista em aceitar certas mostras voltadas ao tema queer sem a aparente homofobia: ao advertir o pagador de impostos de que seu dinheiro está sendo usado para promover a promiscuidade ou a pedofilia (MILLS, 2010: 80-1). No entanto, o fato é que os museus britânicos podem hoje contar com o endosso financeiro público.

Por sua vez, nos museus americanos, o movimento queer procurou dar maior visão para indivíduos e grupos que escapavam da heteronormatividade, focando no gênero como uma construção social, mas ressaltando que a sexualidade não é vista por todos os estudiosos como resultado da biologia, tampouco (LEVIN, 2010: 6. Enquanto uma distinção entre sexo e gênero pode ser benéfica e útil para alguns, já que algumas feministas e alguns teóricos queer enfatizam a distinção entre gênero e sexo biológico para desconstruir a formulação: biologia-é-destino (SCHMIDT \& VOSS 2000: 2-3), para uma das mais influentes autoras de teoria queer, Judith Butler (1990), isso cria impressão de que o sexo biológico é uma página em branco onde 
se inscrevem culturalmente o gênero e a sexualidade. Para Butler, o sexo biológico é também culturalmente construído (p. 6).

A aparente falta de consenso sobre as definições de termos relacionados aos gêneros, às práticas sexuais e à sexualidade é apenas um dos fatores que trazem desconforto aos arqueólogos e curadores quando da organização de mostras sobre o público LGBT-Q. Barbara Voss (2000: 4 e 5) elenca quatro grandes obstáculos para o tratamento da sexualidade por arqueólogos: o essencialismo, a negatividade, a hierarquia e o tratamento lascivo da sexualidade. O axioma do essencialismo estabelece que o sexo é algo natural, imutável, baseado em normas biológicas. Se não é tido como um fenômeno cultural, então muitos arqueólogos entendem que não está condicionado pelos contextos históricos, ficando restrito às instituições como o casamento e a procriação nos estudos arqueológicos e o mesmo se vê nas exibições resultantes de tais trabalhos. A negatividade do sexo é também um obstáculo. O sexo e o erótico são tidos por muitos autores e acadêmicos do mundo ocidental como destrutivo, ameaçador, a não ser que tenha o firme propósito da procriação. Há uma hierarquia da sexualidade, também. O sexo monogâmico voltado à reprodução tem precedência sobre outros atos sexuais. Com isso em mente, o sexo heterossexual domina os estudos e a homossexualidade ou variações das normas heterossexuais são marginalizadas. Por fim, o tratamento do sexo como algo que deve ser exagerado, caricato ou cômico, prejudica certas representações e abordagens mais adequadas aos grupos minoritários ou o estudo de práticas sexuais menos "populares". As abordagens lascivas trivializam o sexo e certos setores da mídia procuram escandalizar seus leitores ao invés de informar algo construtivo. O tablóide inglês The Sun, por exemplo, tem uma longa história de homofobia (MILLS, 2010: 81).

Em vista dos motivos citados acima, as mostras sobre sexualidade podem causar grande controvérsia. Um exemplo são as fotografias do famoso artista Robert Mapplethorpe, que se especializou em retratar homens nus em temas homoeróticos, inclusive de conotação sadomasoquista. Várias de suas obras expostas em museus sofreram algum tipo de censura nos Estados Unidos (FROST, 2010: 138). Ainda que haja tais retrocessos, as repercussões na mídia colaboram para que tais exibições LGBT-Q se tornem ao menos comentadas e se difundam em alguns círculos que de outro modo não se preocupariam muito em refletir sobre a presença de tais temas nos museus.

A maioria das mostras LGBT-Q concentram-se em arte recente ou contemporânea, e o Mundo Antigo parece um pouco negligenciado. Um problema a ser enfrentado é justamente o das nomenclaturas a serem usadas para classificar os artefatos do passado e estabelecer suas ligações com grupos significados como marginais por ideologias predominantes em seu tempo. Para que tudo não se restrinja a uma verdadeira logomaquia, parece ser mais produtivo explicar como certos termos ganham ou perdem ao longo da história seus efeitos semânticos classificatórios nas sociedades, algo ainda mais necessário quando falamos de Antiguidade, por exemplo.

Mesmo termos tidos hoje por muitos como pouco problemáticos podem ser frutos de construções discursivas bastante recentes, sem qualquer significado para sociedades antigas. O próprio termo "homossexualidade" teria sido usado pela primeira vez em um texto alemão anônimo, de 1869 (que tem, comumente, sido atribuído a Karoly Kertbeny), uma palavra que 
primeiro teria sido usada na língua inglesa em 1890, por Charles Chaddock. Foi por este momento que aflorou a percepção de que existiria um tipo diferente de ser humano, que se fazia distinto da maioria por seus desejos e atos sexuais voltados para pessoas do mesmo sexo, e assim, em termos médicos e legais, surgiu o homossexual, uma forma de identidade que se tentou isolar e categorizar, para então reprimir e punir (PETRY, 2010: 1523). Como aponta Michel Foucault, em sua influente História da Sexualidade (2005), o surgimento das categorias homossexual e heterossexual acabou por revelar que não se pode dizer que as sexualidades são formas naturais, pré-discursivas, antes, são todas elas construções culturais.

Mostrar como se desenvolveram as discussões que ora afastam e ora aproximam gênero (o desejo de ser), tradicionalmente tido como cultural, e sexo (o desejo de ter), tido como biológico, pode ser muito útil para compreendermos como conceitos do passado, como os cinaedi, os efeminados entre os romanos, e o crime da sodomia, do sexo não natural, na Idade Média, podem desaparecer, ganhar novos significados, ou serem obliterados em nosso tempo, especialmente tendo em vista o advento da sexualidade enquanto campo de estudo de identidades, fruto do séc. XIX (MILLS, 2010: 82-3). As mostras de vasos eróticos gregos, que retratam cenas homossexuais masculinas não são um fenômeno recente, mas suas exibições de forma organizada para gerar debates e reflexões sobre as condutas e práticas sexuais entre pessoas do mesmo sexo na Antiguidade é algo que vem se consolidando há apenas alguns anos. Um curioso caso que pode ilustrar as mudanças no tratamento de peças consideradas polêmicas pelos museus é o da taça de período romano conhecida como Warren Cup.

\section{A A N I U IDADE NOS MUSEUS: O CASO DA WARREN CUP}

A Warren Cup recebeu seu nome por causa de seu primeiro dono moderno: Edward Perry Warren, também conhecido como Ned Warren (WILLIAMS, 2006: 17). Ned Warren se notabilizou como um ávido colecionador de curiosa erótica. Muitas das peças da sua coleção particular foram doadas em vida para o Museum of Fine Arts de Boston (FROST, 2010: 143-4) e parece certo que aquele museu contou com uma coleção de peças eróticas doadas por Warren por volta de 1908, a chamada The Warren Collection of Erotica (SOX, 1991: 253). Todavia, a coleção só foi exposta pelo Museu de Boston nos anos 1950. O puritanismo da Nova Inglaterra se sentiu afrontado e tinta preta foi aplicada sobre cenas tidas como obscenas, e uma "pessoa" no cargo de curadoria do museu chegou mesmo a mutilar uma das estátuas, cortando-lhe o pênis de mármore e escondendo-o na gaveta de seu escritório. O membro extirpado foi mais tarde encontrado por outro curador, que o devolveu à estátua emasculada (FROST, 2010: 144; SOX, 1991: 120, 253-254).

A Warren Cup é um kantharos de prata, oval, de 11 centímetros de altura (WILLIAMS, 2006: 7, 38). A peça teria sido encontrada nas cercanias de Jerusalém, naquele que teria sido um pequeno lugarejo datado do início do séc. I d.C., o mesmo período associado à sua fabricação. Não há consenso sobre como ou porque a taça teria ido parar lá. O que a faz tão famosa atualmente são as repercussões modernas causadas por seus relevos externos, ricos em detalhes de cenas homoeróticas entre homens 
de variadas idades, inclusive uma cena de sexo entre um jovem adulto e um menino.

A partir da morte de Ned Warren em 1928, a Warren Cup segue um sinuoso percurso até o seu atual local de exibição: o Museu Britânico, em Londres. Em 1953, a Warren Cup chegou de forma pouco clara à Nova Iorque, tendo sido lacrada e considerada pornografia por um oficial da alfândega americana (WILLIAMS, 2006: 30). Devolvida no ano seguinte à Inglaterra, foi oferecida para venda ao Museu Britânico. Mas este se recusou a adquirí-la por causa do teor das representações e porque um dos principais curadores do museu, o Arcebispo de Canterbury, poderia se enfurecer com tamanha ousadia. Sem alarde, a Warren Cup acabou vendida a um colecionador particular que a levou para fora da Inglaterra. Após ser corajosamente exibida ao público em meados dos anos 1980 no Antikenmuseum, na Suíça, a Warren Cup foi doada em 1992, anonimamente, ao Metropolitam Museum of Art de Nova Iorque, de onde foi removida seis anos mais tarde, sem explicações, e vendida a um comerciante britânico. Foi finalmente comprada pelo Museu Britânico em 1999, por quase dois milhões de libras esterlinas, que passou a exibi-la em 2006 (WILLIAMS, 2006: 30-1).

É sintomático das percepções modernas da homossexualidade e do homoerotismo que a Warren Cup tenha tido tanta dificuldade em ser exibida ao público ao longo do séc. XX. O desconforto com as imagens dos relevos da Warren Cup denuncia um longo histórico de censura ao erótico nos museus da Europa. Em 1795, o museu de Portici, Herculano, possuía uma sala reservada para os objetos considerados obscenos e, em 1813, foi criado naquele museu o Gabinete dos Objetos Obscenos (FROST, 2010: 140), com grandes restrições de acesso ao público em geral.

Já na década de 1830, certos objetos tidos como inapropriados foram também segregados no Museu Britânico e, nos anos 1840 e 1850, foi criado o Museum Secretum para dar-lhes abrigo e mantê-los longe de olhos mais suscetíveis aos apelos "contranatura" retratados nas peças. O último depósito no Museum Secretum foi feito em 1953, e nos anos 1960 houve uma maior liberalização da censura e, em 1967, o Sexual Offences Act reduziu o peso criminal da homossexualidade na Inglaterra e no País de Gales. Ainda assim, desde então, não foram muitas as exibições que trataram do tema da sexualidade (FROST, 2010: 140-1), menos ainda de temas ligados aos grupos LGBT-Q.

Atualmente, a Warren Cup está em exposição permanente no Museu Britânico, na galeria 70, dedicada à Roma como "cidade imperial". Fig. 1. O curador da exibição, Dyfri Williams, explica que o propósito do museu é mostrar como o passado se distinguia do presente, e provocar a reflexão sobre as atitudes que hoje expressamos a respeito das práticas sexuais (FROST, 2010:144).

A peça sofreu interpretações diversas desde 1998 e foi tema de uma mostra chamada de The Warren Cup: sex and society in ancient Greece and Rome, entre maio e julho de 2006. O Museu Britânico resolveu associar a história do cálice às atitudes modernas diante do homoerotismo e, na exposição, havia cartas do séc. XVIII, imagens do filme Brokeback Mountain, e imagens do Japão da primeira metade do séc. XIX, entre outras. A resposta dos visitantes foi muito positiva. A Warren Cup foi mostrada também no Yorkshire Museum, na exposição The Warren Cup: The Classical ideal, de 
dezembro de 2006 a janeiro de 2007.

Motivos e temas sexuais faziam parte do quotidiano da decoração de artefatos na arte clássica. Mas os visitantes podem desconhecer os usos corriqueiros de tais peças porque os museus não anunciam o fato ou se mostram hesitantes e preocupados em demasia com os resultados das mostras. A exibição de artefatos como a Warren Cup contribui para a reflexão sobre nossas próprias atitudes diante do sexo em nosso tempo.

\section{CONSI DER A ÇÕ ES F I N I S}

Em 2006, a ONG britânica Proud Heritage lançou uma pesquisa chamada de Proud Nation Survey entre os museus britânicos, pedindo que registrassem suas exibições $L G B T-Q$ junto àquela entidade. A ideia era criar um banco de dados online que mapeasse objetos, histórias e memórias das populações LGBT-Q (FROST, 2010: 148). Os resultados poderiam ser vistos no site oficial da entidade, que, no entanto, oferecia poucas informações até o momento desta publicação. Contudo, o site <www.culture24.org.uk/> permite a busca por exibições LGBT em museus britânicos, com bons e surpreendentes resultados.

As exibições nos museus são valiosas ferramentas de inclusão social. A materialidade serve como legitimadora de identidades e institucionaliza construções sociais precárias, transformando-as em fatos sociais. Por outro lado, pode servir como valioso recurso em práticas que transformam ou desestabilizam essas mesmas identidades sociais (VOSS, 2008: 23). O engajamento social dos museus com o público LGBT-Q é importante e os arqueólogos e curadores vêm, aos poucos, promovendo narrativas, e estendendo debates sobre os problemas sociais e a diversidade sexual, tanto antiga quanto moderna. Enquanto as teorias arqueológicas queer podem auxiliar na desconstrução de discursos normativos, transpor a história queer para o público acaba por contestar tais normas e por revelar um pouco mais dos mecanismos sociais envolvidos em suas construções.

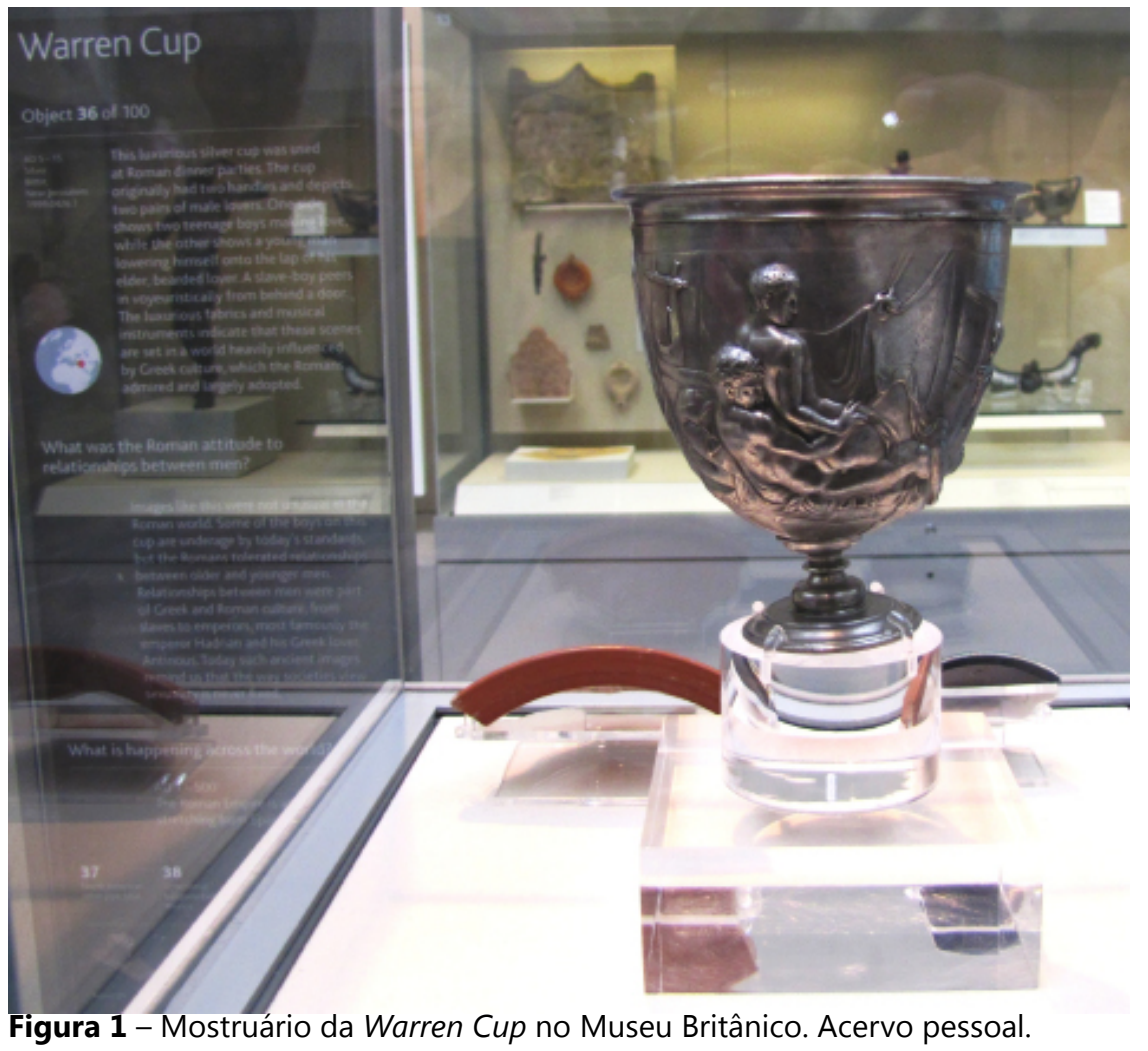




\section{B I B L I O G R A F I A}

BARTHES, Roland (1986) "The plates of the encyclopedia" In: Sontag, S. (ed.) A Barthes Reader. Nova Iorque: Hill \& Wang. 218-35.

BUTLER, Judith (1990) Gender Trouble: Feminism and the Subversion of Identity. New York: Routledge. COBB, Hannah (2005) "Straight down the line? A queer consideration of hunter-gatherer studies in northwest Europe". World Archaeology 37(4). 630-6.

CONKEY, Margaret W. and J.D. Spector (1984) "Archaeology and the Study of gender". Advances in Archaeological Method and Theory 7. 1-38.

CROUCHER, Karina (2005) "Queering Near Eastern archaeology". World Archaeology 37(4). 610-20.

DOWSON, Thomas A. (2000) "Why queer archaeology?". World Archaeology 32. 161-5.

FOUCAULT, Michel (2005) História da Sexualidade 1: a vontade de saber. 16a edição. São Paulo: Graal.

FROST, Stuart (2010) "The Warren Cup: Secret Museums, Sexuality, and Society." In: LEVIN, A. K. (ed.) (2010) Gender, Sexuality and Museums. Londres: Routledge. 138-150.

FUNARI, Pedro P. A. (2007) "Considerações sobre o profissional de museu e sua formação". In: FUNARI, P. P. A. (ed.) (2007) Arqueologia e Patrimônio. Erechim, RS: Habilis Editora. 97-106.

FUNARI, Pedro P. A.; A. Zarankin e E. Stovel (ed.) (2005) Global Archaeological Theory: Contextual Voices and Contemporary Thoughts. Nova Iorque: Kluwer/Plenum.

GABRIEL, Peter (2010) "Why grapple with queer when you can fondle it? Embracing our erotic intelligence". In: LEVIN, A. K. (ed.) (2010). 71-9.

GERO, Joan M. \& M.W. Conkey (ed.) (1991) Engendering Archaeology: women and prehistory. Cambridge, MA: Blackwell.

HODDER, Ian (2005) "Symbolic and Structuralist Archaeology". In: Renfrew et al (2005). 254-9.

JENKINS, Keith. (1991) Re-thinking History. Londres: Routledge.

KNAPP, Alan B. (1998) "Boys will be boys: masculinist approaches to a gendered Archaeology". In: Whitley, D. S. (ed.) (1998). 241-9.

LEVIN, Amy K. (ed.) (2010) Gender, Sexuality, and Museums. Nova Iorque: Routledge.

MENESES, Ulpiano T. B. (1995) "Resposta aos Comentários". Anais do Museu Paulista. São Paulo N. Ser. v. 3, jan. dez. 1995. 103-22.

MILLS, Robert (2010) "Queer is here? Lesbian, gay, bisexual and transgender histories and public culture". In: LEVIN, A. K. (ed.) (2010). 80-8.

NELSON, S.M. (2005) "Gender Archaeology". In: Renfrew et al (2005a). 127-33.

PETRY, Michael (2010) "Hidden histories: experience of curating a male same-sex exhibition and the problems encountered". In: LEVIN, A. K. (ed.) (2010).151-62.

RENFREW, Colin e P. Bahn (ed.) (2005) Archaeology: The Key Concepts. Oxon: Routledge.

SCHMIDT, Robert. A. \& B. Voss (ed.) (2000) Archaeologies of Sexuality. Nova Iorque: Routledge.

SCHWARZER, Marjorie (2010) "Women in the temple: gender and leadership in museums". In: LEVIN, A. K. (ed.) (2010). 17-27.

SEDGWICK, Eva K. (1990) Epistemology of the Closet. Berkeley: University of California Press.

SHANKS, Michael \& C. Tilley (1992) Re-Constructing Archaeology. Cambridge: CUP.

SOX, David (1991) Bachelors of Art: Edward Perry Warren and the Lewes House Brotherhood. Londres: Fourth State.

TILLEY, Christopher (1998) "Archaeology as Social-Political Action in the Present". In: Whitley, D. S. (ed.) (1998). 305-30.

VOSS, Barbara L. (2000) "Feminisms, queer theories, and the archaeological study of past sexualities". World Archaeology 32. 180-92.

VOSS, Barbara L. (2008) The Archaeology of Ethnogenesis: Race and Sexuality in Colonial San Francisco. Los Angeles: University of California Press.

WHITLEY, David S. (1998) "New Approaches to Old Problems: Archaeology in Search of an Ever Elusive Past". In: Whitley D. S. (ed.) (1998). 1-28. 
WHITLEY, David S. (ed.) (1998) Reader in Archaeological Theory: Post-Processual and Cognitive Approaches. Londres: Routledge.

WILLIAMS, Dyfri (2006) The Warren Cup. Londres: The British Museum Press. 